appearing Euramerican members of this group and the new African species (Fig. 2). The Moradi amphibians probably represent relicts of a basal group that had long gone extinct elsewhere. In all other regions of Pangaea, more advanced temnospondyls form the bulk of amphibian diversity during the Late Permian, with archegosauroids, dvinosaurians, eryopoids and dissorophoids present in Russia and China, rhinesuchids and archegosauroids present in southern Africa and South America ${ }^{9,17-20}$, and advanced stereospondyls present in Australia ${ }^{21}$.

Therapsid-dominated faunas composed of the same, or closely related, species have long been known from areas as distant as South Africa and Russia ${ }^{13-15,22,23}$, and indicate that long-distance, bidirectional north-south exchange was commonplace on Pangaea during the Permian period. In these faunas, dicynodonts are the dominant large-bodied herbivores and advanced temnospondyls represent the principal aquatic predators. Despite its central geographical location (within $15^{\circ}$ of the palaeoequator), the fauna from Niger does not overlap at the generic level with the higher-latitude faunas. Dicynodonts have yet to be described from the Moradi Formation $^{2-6}$, and we found no evidence for their presence, despite intensive fieldwork. Instead, an abundance of captorhinid and pareiasaurian herbivore remains suggests that these taxa were the chief plant consumers ${ }^{3-5}$.

Climate seems to have had an important role in isolating tetrapods from low latitudes from those at mid- and high latitudes during the Late Permian period (Fig. 3). Geological data and climate simulations suggest that desert-like conditions replaced a more moderate climate in central Pangaea by Middle Permian times ${ }^{10-12}$. Along with the markedly different floral provinces that characterize northern and southern continents during the Late Permian ${ }^{11}$, this change in climate may have isolated pockets of a once widespread tetrapod fauna 9 . This hypothesis accounts for the early divergence of the new temnospondyls from Niger, the highly autapomorphic anatomy of the contemporary reptiles ${ }^{3-5}$, and the similar captorhi$\mathrm{nid} /$ pareiasaur fauna recovered from low palaeolatitudes in Upper Permian rocks in Morocco $^{14,24}$.

The degree to which climate influenced the evolutionary biogeography of terrestrial vertebrates towards the end of the Permian period has been previously underestimated because of uneven latitudinal sampling. Mid-to-high-latitude faunas in Russia and South Africa, although fossil-rich and comparatively well known, may have evolved under similar climatic conditions and were probably linked by coastal migration routes. Our discoveries reveal a surprisingly distinctive Permian terrestrial community at low palaeolatitude, and highlight the influence of climate change on large-scale patterns of biotic evolution.

Received 18 October 2004; accepted 25 January 2005; doi:10.1038/nature03393.

1. Ministère des Mines et de l'Hydraulique, Direction des Mines et de la Géologie. Afasto, Carte Géologique 1:200,000, Notice Explicative (1977).

2. Taquet, P. Un exemple de datation et de corrélation stratigraphique basé sur les Captorhinomorphes (Reptiles cotylosauriens). Mém. Bureau Recherch. Géol. Min. 77, 407-409 (1972).

de Ricqlès, A. \& Taquet, P. La faune de vertébrés du Permien Supérieur du Niger. I. Le captorhinomorphe Moradisaurus grandis (Reptilia, Cotylosauria). Ann. Paléontol. 68, 33-106 (1982).

4. Sidor, C. A., Blackburn, D. C. \& Gado, B. The vertebrate fauna of the Upper Permian of Niger. II. Preliminary description of a new pareiasaur. Palaeontol. Afr. 39, 45-52 (2003).

5. O'Keefe, F. R., Sidor, C. A., Larsson, H. C. E., Maga, A. \& Ide, O. The vertebrate fauna of the Upper Permian of Niger. III. Ontogeny and morphology of the hindlimb of Moradisaurus grandis (Captorhinidae: Moradisaurinae). J. Vert. Paleontol. (in the press).

6. Taquet, P. Géologie et Paléontologie du Gisement de Gadoufaoua (Aptien du Niger) 1-191 (Cahiers de Paléontologie, Paris, 1976).

7. Sequeira, S. E. K. The skull of Cochleosaurus bohemicus, a temnospondyl from the Czech Republic (Upper Carboniferous) and cochleosaurid interrelationships. Trans. R. Soc. Edinb. Earth Sci. 94, 21-43 (2004).

8. Milner, A. R. \& Sequeira, S. E. K. A cochleosaurid temnospondyl amphibian from the Middle Pennsylvanian of Linton, Ohio, U.S.A. Zool. J. Linn. Soc. 122, 261-290 (1998).

9. Milner, A. R. in Palaeozoic vertebrate biostratigraphy and biogeography (ed. Long, J. A.) 324-353 (Belhaven, London, 1993).

10. Gibbs, M. T. et al. Simulations of Permian climate and comparisons with climate-sensitive sediments. J. Geol. 110, 33-55 (2002).

11. Rees, P. M. et al. Permian phytogeographic patterns and climate data/model comparisons. J. Geol. 110 $1-31$ (2002).
12. Ziegler, A. M., Hulver, M. L. \& Rowley, D. B. in Late Glacial and Postglacial Environmental Changes (ed. Martini, I. P.) 111-146 (Oxford Univ. Press, New York, 1997).

13. Rubidge, B. S. \& Sidor, C. A. Evolutionary patterns among Permo-Triassic therapsids. Annu. Rev. Ecol. Syst. 32, 449-480 (2001).

14. Battail, B. A comparison of Late Permian Gondwanan and Laurasian amniote faunas. J. Afr. Earth Sci. 31, 165-174 (2000).

15. Modesto, S. P. \& Rybczynski, N. in The Age of Dinosaurs in Russia and Mongolia (eds Benton, M. J., Shishkin, M. A., Unwin, D. M. \& Kurochkin, E. N.) 17-34 (Cambridge Univ. Press, New York, 2000). 16. Bakker, R. T. Anatomical and ecological evidence of endothermy in dinosaurs. Nature 238, 81-85 (1972)

17. Damiani, R. J. A systematic revision and phylogenetic analysis of Triassic mastodonsauroids (Temnospondyli: Stereospondyli). Zool. J. Linn. Soc. 133, 379-482 (2001).

18. Yates, A. M. \& Warren, A. A. The phylogeny of the 'higher' temnospondyls (Vertebrate: Choanata) and its implications for the monophyly and origins of the Stereospondyli. Zool. J. Linn. Soc. 128, 77-121 (2000)

19. Schoch, R. R. \& Milner, A. R. in Encyclopedia of Paleoherpetology (ed. Wellnhofer, P.) Part 3B, 1-203 (Verlag Dr. Friedrich Pfeil, Munich, 2000)

20. Dias, E. V. \& Barberena, M. C. A temnospondyl amphibian from the Rio do Rasto Formation, Upper Permian of southern Brazil. An. Acad. Bras. Cienc. 73, 135-143 (2001).

21. Marsicano, C. A. \& Warren, A. A. The first Palaeozoic rhytidosteid record: Trucheosaurus majo Watson, 1956 from the Late Permian of Australia, and a reassessment of the Rhytodosteidae (Amphibia: Temnospondyli). Bull. Brit. Mus. Nat. Hist. (Geol.) 54, 147-154 (1998).

22. Angielczyk, K. D. \& Kurkin, A. A. Phylogenetic analysis of Russian Permian dicynodonts (Therapsida: Anomodontia): implications for Permian biostratigraphy and Pangaean biogeography. Zool. J. Linn. Soc. 139, 157-212 (2003).

23. Lucas, S. G. in Carboniferous and Permian of the World (eds Hills, L. V., Henderson, C. M. \& Bamber E. W.) 479-491 (Canadian Society of Petroleum Geologists Memoir 19, Calgary, Alberta, 2002).

24. Jalil, N.-E. Continental Permian and Triassic vertebrate localities from Algeria and Morocco and their stratigraphical correlations. J. Afr. Earth Sci. 29, 219-226 (1999).

Supplementary Information accompanies the paper on www.nature.com/nature.

Acknowledgements We thank A. Beck, D. Blackburn, J. Conrad, A. Dindine, E. Duneman, B. Gado, T. Lyman, G. Lyon, R. Sadlier and G. Wilson for assistance in the field; A. Crean, E. Love, V. Heisey and J. Groenke for fossil preparation; and S. Spilkevitz for help with Fig. 3. We thank $\mathrm{H}$. Salissou of the Ministère des Enseignements Secondaire et Supérieur, de la Recherche et de la Technologie for permission to conduct fieldwork. We acknowledge the National Geographic Society for support.

Competing interests statement The authors declare that they have no competing financial interests.

Correspondence and requests for materials should be addressed to C.A.S. (casidor@nyit.edu).

\section{Hair cell synaptic ribbons are essential for synchronous auditory signalling}

\section{Darina Khimich ${ }^{1}$, Régis Nouvian ${ }^{1,2}$, Rémy Pujol ${ }^{2}$, Susanne tom Dieck ${ }^{3 \star}$ Alexander Egner ${ }^{4}$, Eckart D. Gundelfinger ${ }^{3}$ \& Tobias Moser}

${ }^{1}$ Department of Otolaryngology and Center for Molecular Physiology of the Brain, University of Goettingen, 37099 Goettingen, Germany

${ }^{2}$ INSERM U583-INM, BP 74103 and CRIC, University of Montpellier, 34091 Montpellier Cedex 5, France

${ }^{3}$ Department of Neurochemistry and Molecular Biology, Leibniz Institute for Neurobiology, 39118 Magdeburg, Germany

${ }^{4}$ Department of NanoBiophotonics, Max Planck Institute for Biophysical Chemistry, Am Fassberg 11, D-37077 Goettingen, Germany

* Present address: Department of Neuroanatomy, Max Planck Institute for Brain Research, 60528 Frankfurt/M, Germany

Hearing relies on faithful synaptic transmission at the ribbon synapse of cochlear inner hair cells (IHCs) $^{1-3}$. At present, the function of presynaptic ribbons at these synapses is still largely unknown ${ }^{1,4}$. Here we show that anchoring of IHC ribbons is impaired in mouse mutants for the presynaptic scaffolding protein Bassoon. The lack of active-zone-anchored synaptic ribbons reduced the presynaptic readily releasable vesicle pool, and impaired synchronous auditory signalling as revealed by 
recordings of exocytic IHC capacitance changes and soundevoked activation of spiral ganglion neurons. Both exocytosis of the hair cell releasable vesicle pool and the number of synchronously activated spiral ganglion neurons co-varied with the number of anchored ribbons during development. Interestingly, ribbon-deficient IHCs were still capable of sustained exocytosis with normal $\mathrm{Ca}^{2+}$-dependence. Endocytic membrane retrieval was intact, but an accumulation of tubular and cisternal membrane profiles was observed in ribbon-deficient IHCs. We conclude that ribbon-dependent synchronous release of multiple vesicles at the hair cell afferent synapse is essential for normal hearing.

The afferent synapse of the cochlear IHC is specialized for encoding acoustic signals with high temporal precision over long periods of time ${ }^{1}$. Presynaptic active zones in mature IHCs usually contain a single synaptic ribbon-a submicrometre, electron-dense structure tethering synaptic vesicles ${ }^{2}$. Each spiral ganglion neuron (SGN) receives input from only one IHC synapse ${ }^{3}$. Synaptic ribbons are a hallmark of neurons that transmit graded signals, such as hair cells, retinal photoreceptors and bipolar neurons, pinealocytes and electroreceptors ${ }^{1,4,5}$. Although some molecular components of the ribbon have recently been identified ${ }^{6-8}$, the role of synaptic ribbons in transmitter release remains unclear ${ }^{1,4,5}$. The prevailing view depicts ribbons as conveyor belts for synaptic vesicles, supporting high rates of sustained transmitter release. The investigation of ribbon-deficient synapses, generated by genetic manipulation, offers a direct approach to understanding the function of synaptic ribbons. A mouse mutant for the presynaptic scaffolding protein, Bassoon $^{9}$, lacks synapse-anchored ribbons in retinal photoreceptors and has impaired vision ${ }^{10}$. The specific role of the ribbon in transmitter release has remained elusive because synaptic pathophysiology could not be explored at the level of the photoreceptors ${ }^{10}$.

Here, we exploit the accessibility of cochlear hair cells for in vitro recording ${ }^{1}$ to study the consequences of ribbon-deficiency in Bassoon mutants, from the systems response down to the level of the hair cell synapse. Immunohistochemistry of the organs of Corti from 8-week-old mice identified the ribbon-containing IHC synapse as juxtaposed spots of the presynaptic ribbon component RIBEYE $^{6}$ and postsynaptic glutamate receptors (GluR, Figs 1a, g, h and $2 \mathrm{~g}$, and Supplementary Movies). Antibodies against the RIBEYE A-domain and against the transcriptional repressor carboxyterminal binding protein 2 ( $\mathrm{CtBP} 2$, which is transcribed from the same gene and only differs from the RIBEYE B-domain by 20 amino-terminal amino acids ${ }^{6}$ ) produced virtually identical staining patterns (Supplementary Fig. 1a). We used the anti-CtBP2 antibody in subsequent experiments because it stained both ribbons and nuclei (Fig. 1a), and therefore allowed us to quantify the number of ribbon-containing synapses per IHC.

A number of Bassoon (Fig. 1a, lower left panel) and Piccolo (Fig. 1a, lower right panel and Supplementary Fig. 1b-d) immunosignals overlapped with IHC ribbons. Some additional, nonoverlapping staining of Bassoon and Piccolo probably represented efferent nerve terminals innervating afferent dendrites (axodendritic synapses, Supplementary Fig. 1e, f). Figure 1b is an electron micrograph showing a representative synapse of an 8-week-old wild-type IHC. The ovoid, electron-dense ribbon tethers a halo of synaptic vesicles and is attached to the presynaptic density. A representative IHC synapse from a mutant littermate (Fig. 1c) shows pre- and postsynaptic densities but lacks the ribbon (for quantification of morphological data see Supplementary Table 1). Moreover, the active zone is occupied by tubular and cisternal membrane profiles. These profiles are reminiscent of the large endosomal membrane compartments previously described in ribbon synapses following depolarization ${ }^{11-13}$, and will be referred to as 'cisterns' (as in ref. 12). A pair of ribbons, embedded in another aggregate of cisterns, was found floating in the cytosol at some distance from the synapse (Fig. 1c, magnified in Fig. 1d). Numerous cisternal aggregates were observed in IHCs from each of the six mutant mice analysed, whereas only a few, isolated cisterns were found in a fraction (2/7) of wild-type animals. Membrane profiles resembled cisterns when they were distant from floating (Fig. 1d) or anchored ribbons (Fig. 1e), whereas they appeared vesicle-like when close to ribbons. Future experiments will be required to determine the origin and nature of the cisterns in Bassoon-deficient IHCs.

Next, we used the high axial resolution of multifocal 4Pimicroscopy ${ }^{14,15}$ to estimate the ribbon size from large samples of wild-type and mutant RIBEYE immunofluorescent spots. Deconvolved three-dimensional (3D)-reconstructions of RIBEYE- and GluR-labelled afferent synapses showed that both signals were closely juxtaposed in wild-type IHCs (Fig. 1g). In line with the electron microscopy data, mutant IHCs showed predominantly ribbon-deficient synapses (isolated postsynaptic spots in Fig. 1h). As illustrated in the representative 3D-reconstructions of IHC RIBEYE/CtBP2 immunofluorescence (Fig. 1i, j), wild-type IHCs showed many submicrometre RIBEYE spots, whereas mutant IHCs had far fewer, and mainly large, RIBEYE-positive spots

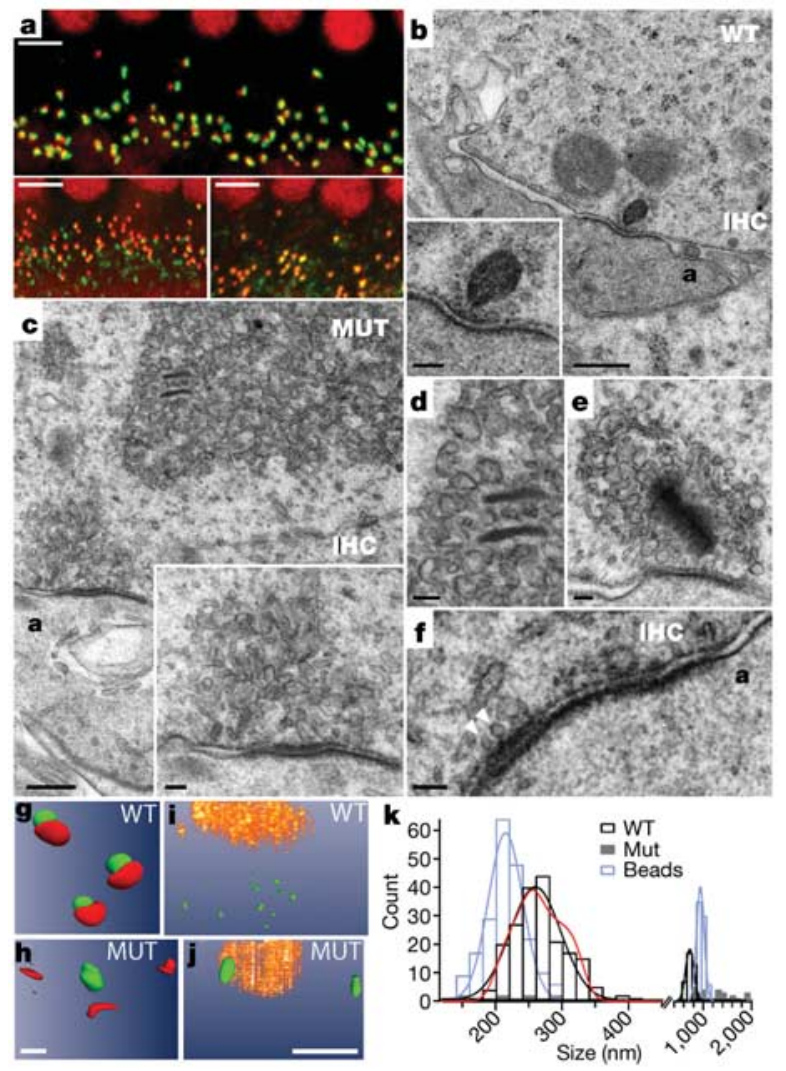

Figure 1 Bassoon anchors synaptic ribbons at IHC active zones. a, Confocal stacks of the organ of Corti immunostained for (top panel) RIBEYE (red) and GluR (green), (lower left) RIBEYE and Bassoon (green), or (lower right) RIBEYE and Piccolo (green). b-f, Electron micrographs of wild-type (b) and mutant (c-f) IHC ribbon synapses (shown at higher magnification in insets; the afferent dendrite is marked ' $a$ '. $\mathbf{d}$, Floating ribbons in $\mathbf{c}$ shown at higher magnification. e, 'Medusa-like' ribbon of a mutant IHC. $\mathbf{f}$, Mutant ribbondeficient synapse with docked synaptic vesicles (arrowheads). $\mathbf{g}-\mathbf{j}$, 4Pi microscopy of RIBEYE (green) and juxtaposed postsynaptic GluR (red) spots of wild-type (g) and mutant (h) afferent synapses after deconvolution. RIBEYE spots (green) of single wild-type (i) and mutant (j) IHCs (nuclear CtBP2 staining rendered in gold). $\mathbf{k}$, Size distributions of 239 wild-type (black) and 43 mutant (grey) RIBEYE spots, as well as of latex beads (blue) with 216- and 1,000-nm diameters. Red line shows ellipsoid model, other lines show spherical model (gaussian fits). Scale bars, $5 \mu \mathrm{m}(\mathbf{a}, \mathbf{i}$ and j) $500 \mathrm{~nm}(\mathbf{g}, \mathbf{h}), 400 \mathrm{~nm}(\mathbf{b}, \mathbf{c}), 100 \mathrm{~nm}$ (insets to $\mathbf{b}$ and $\mathbf{c} ; \mathbf{d}-\mathbf{f}$ ). 
(65\% large spots compared with $16 \%$ in wild type). The estimates of ribbon size obtained from mutant and wild-type RIBEYE spots (described in Supplementary Methods) are plotted in Fig. 1k. The size distribution of wild-type ribbons had a peak at $260 \mathrm{~nm}$. It was approximated by a model that assumed an ellipsoid shape of the average wild-type ribbon and a random orientation of the ribbon with respect to the optical axis. The three principal axes of the average wild-type ribbon were estimated as 201, 255 and $332 \mathrm{~nm}$ (red line in Fig. 1k, Supplementary Table 1 and Supplementary Methods). The large RIBEYE spots in mutant and wild-type IHCs probably corresponded to stacks of floating ribbons, as observed using electron microscopy (for example, Fig. 1d).

Next, we measured cochlear responses in 8 -week-old mice to quantify the consequences of IHC ribbon deficiency for auditory function. Figure 2 documents the analysis of a representative pair of wild-type and mutant littermates. First, we recorded auditory brainstem responses to clicks and short tone bursts in order to assess synchronized neural activity in the ascending auditory pathway (Fig. 2a, b). Responses from the mutant showed distortion of auditory brainstem response waveforms and increased thresholds. The first peak (I) was reduced and delayed for supra-threshold stimuli, reflecting impaired compound action potential in the mutant spiral ganglion. To ensure that this reduction of synchronous SGN activation was not due to defects in outer hair cell amplification, we also measured distortion product otoacoustic emissions ${ }^{16}$, and found them to be similar in both mutant and wild type (Fig. 2c, d). Thus, IHC ribbon-deficiency caused reduced neural output despite intact outer hair cell function, as confirmed by electrocochleography and otoacoustic emissions in additional experiments (Supplementary Fig. 2). A combination of pathological auditory brainstem responses with intact otoacoustic emissions defines human auditory neuropathy, a peripheral auditory disorder that is associated with poor speech discrimination. The cellular mechanisms of auditory neuropathy are not yet understood, but may involve defects of IHCs or SGNs ${ }^{17}$.

Next, we performed a patch-clamp analysis of presynaptic IHC function, using the same mice to test the hypothesis that synaptic dysfunction underlies their auditory neuropathy. Fast exocytosis (indicated by membrane capacitance increments in response to short stimuli ${ }^{18}$ ) was strongly decreased in mutant IHCs (Fig. 2e, f), and $\mathrm{Ca}^{2+}$ current was reduced. The organs of Corti were immunostained in order to quantify the number of ribbon-containing synapses (Fig. 2g), as introduced in Fig. 1a and illustrated by Supplementary Movies 1a and b. A strong reduction in synapseanchored ribbons was observed in the mutant. Both genotypes showed comparable numbers of postsynaptic spots. The morphological findings are summarized in Supplementary Table 1, and Fig. $2 \mathrm{~h}$ correlates the morphological and physiological results obtained from five mutant and seven wild-type mice. Data from two wild-type and three mutant mice were excluded because of uncertain outer hair cell function (poor otoacoustic emissions). In summary, the lack of synapse-anchored ribbons caused a reduction in fast exocytosis and in synchronous synaptic activation of SGNs.

This conclusion was further supported by three observations. First, we observed larger numbers of synapse-anchored ribbons in both wild-type and mutant IHCs of 3-week-old mice (just after the onset of hearing), which correlated with increased presynaptic IHC and postsynaptic SGN responses when compared with 8-week-old mice of the same genotype. The reduction in anchored ribbons probably reflected developmental changes in the number of IHC ribbons $^{19}$. Figure 3 a correlates fast IHC exocytosis (membrane capacitance increments in response to 10 -ms depolarization) and SGN compound action potential amplitudes with the number of synapse-anchored ribbons over all four groups. $\mathrm{Ca}^{2+}$ currents were significantly reduced in mutant IHCs of either age (Fig. 3a), possibly owing to insufficient recruitment and/or stabilization of $\mathrm{Ca}_{\mathrm{V}} 1.3$ channels at the active zone. They showed, however, a normal voltage-dependence of activation (Supplementary Fig. 3a). This impaired $\mathrm{Ca}^{2+}$ influx might contribute to the synaptic defect. However, $\mathrm{Ca}^{2+}$ currents were comparable between 3- and 8-weekold IHCs of each genotype, yet their synaptic functions differed. This argues for a genuine dependence of hair cell synaptic function on the presence of functional ribbons. Furthermore, we did not observe the mutant exocytic phenotype when we reduced the $\mathrm{Ca}^{2+}$ current in 8-week-old wild-type IHCs to the level in the mutants by
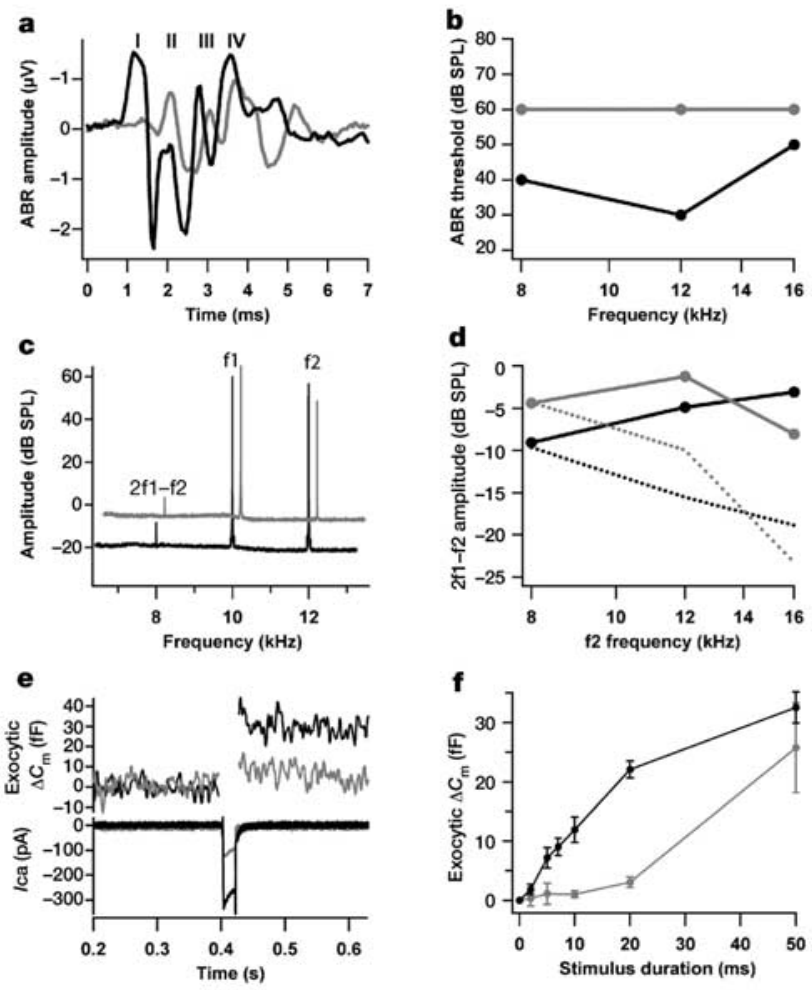

h
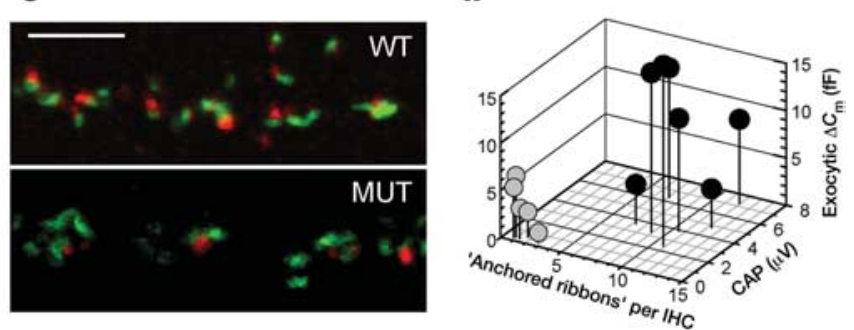

Figure 2 Synaptic ribbons are essential for hearing and fast exocytosis from hair cells Analysis of a pair of mutant (grey) and wild-type (black) mice. a, Auditory brainstem response evoked by suprathreshold clicks $(80 \mathrm{~dB})$, peaks indicated with roman numbers. b, Auditory brainstem audiograms obtained by tone burst stimulation. c, Power spectrum of the microphone signal showing the 2f1-f2 distortion product otoacoustic emission (DPOAE), as well as the primary tones (f1 and f2), mutant data slightly shifted for better visibility. d, Distortion product-audiogram. Markers show 2f1-f2 DPOAE levels, dotted lines show noise floor around 2f1-f2. e, Representative $\mathrm{Ca}^{2+}$ currents $\left(I_{\mathrm{Ca}}\right)$ and $C_{\mathrm{m}}$ changes recorded from wild-type and mutant IHCs (20-ms step depolarization). f, Kinetics of exocytosis constructed from $\Delta C_{\mathrm{m}}$ of the same IHCs in response to depolarization of varying durations. Wild-type and mutant $\Delta C_{\mathrm{m}}$ differed significantly for 5,10 and $20 \mathrm{~ms}$ depolarizations. Errors are s.e.m. g, Immunostaining for RIBEYE (red) and GluR (green) of IHC afferent synapses. Single confocal sections through 4 neighbouring IHCs. Scale bar, $5 \mu \mathrm{m}$. $\mathbf{h}$, The diagram relates the mean number of synapse-anchored ribbons per IHC, fast exocytosis ( $\Delta C_{\mathrm{m}}$ in response to 10 -ms depolarization) and compound action potential (CAP) amplitude (approximated by auditory brainstem response peak I amplitude) for individual mutant (grey) and wild-type (black) mice (analysed as in $\mathbf{a}-\mathbf{g}$ ). 
decreasing the extracellular $\mathrm{Ca}^{2+}$ concentration from 10 to $2 \mathrm{mM}$ (asterisks in Fig. 3). Finally, we observed a reduction in fast exocytosis per unit of $\mathrm{Ca}^{2+}$ influx in mutant IHCs, although the $\mathrm{Ca}^{2+}$ sensitivity of release appeared to be unchanged when considering sustained exocytosis (Supplementary Fig. 3b). Mutant IHCs showed robust sustained exocytosis (Fig. 4) and endocytic membrane retrieval (Fig. 3b). Together, these observations indicate that the synaptic dysfunction of Bassoon mutant mice was primarily due to the reduction of synapse-anchored IHC ribbons, rather than to reduced $\mathrm{Ca}^{2+}$ influx or a general exocytic defect in the absence of functional Bassoon. This is consistent with a primary role for Bassoon in synaptic anchoring of ribbons ${ }^{10}$.

We then related membrane capacitance increments in large samples of ribbon-deficient and normal IHCs to their synapse morphology to dissect ribbon-dependent exocytosis and the mechanism for synaptic dysfunction. Exocytosis of 8-week-old wild-type IHCs was approximated by the sum of a small, fast secretory component and a large, slow component (Fig. 4). We interpret the fastest discernible component (time constant, $\tau \approx 9 \mathrm{~ms}$ ) as exocytosis of the readily releasable vesicle pool $(\mathrm{RRP})^{20}$. The total IHC RRP was estimated to $\sim 18 \mathrm{fF}$ or 640 synaptic vesicles by the model fit (conversion factor of $28 \mathrm{aF}$ per synaptic vesicle, Supplementary Table 1). Mutant exocytosis was
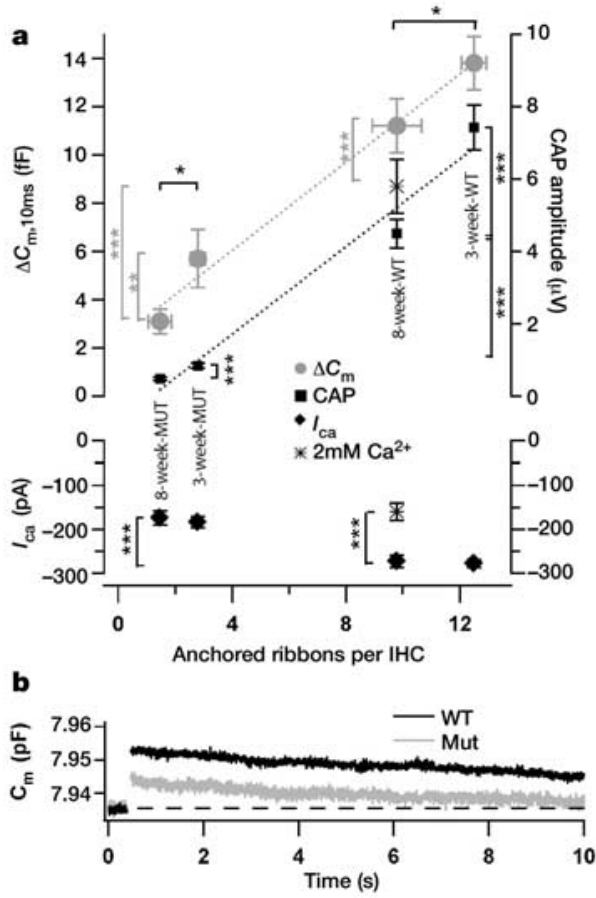

Figure 3 Fast exocytosis and compound action potential amplitude correlate with the number of anchored ribbons per IHCs during development. a, Mean $\Delta C_{\mathrm{m}}$ (circles, upper panel) in response to 10-ms depolarization. Corresponding peak $\mathrm{Ca}^{2+}$ currents (diamonds, lower panel) and amplitude of auditory brainstem response peak I (squares, upper panel; responses to $80 \mathrm{~dB}$ clicks) of 3- and 8-week-old wild-type (WT) and mutant (Mut) mice were related to the numbers of synapse-anchored ribbons per IHC. $\Delta C_{\mathrm{m}}$ and $\mathrm{Ca}^{2+}$ currents of 8-week-old wild-type IHCs were recorded at both $10 \mathrm{mM}(n=25 \mathrm{IHCs})$ and $2 \mathrm{mM}$ extracellular $\mathrm{Ca}^{2+}$ (big asterisks, $n=7 \mathrm{HCS}$ ). All other $\mathrm{HCS}$ were recorded at $10 \mathrm{mM}$ extracellular $\mathrm{Ca}^{2+}(n=24 \mathrm{HCs}$ for 8-week-old mutant and $n=12 \mathrm{HCS}$ for both 3-week-old wild-type and mutant IHCs). Auditory brainstem results were obtained from 28 (wild-type) and 21 (mutant) ears of 8-week-old mice as well as from 14 (wild-type) and 6 (mutant) ears of 3-week-old mice. Counting of synapse-anchored ribbons was based on 80 wild-type and 60 mutant IHCs of 8-week-old mice, and on 78 wild-type and 94 mutant IHCs of 3-week-old mice. Dotted lines represent linear regressions (correlation coefficients $>0.95$ ). All errors are s.e.m. $\mathbf{b}$, Average exocytic and endocytic capacitance responses of 3-week-old wild-type and mutant IHCs to 20-ms depolarization. subtracted to estimate the 'ribbon-dependent' RRP of $\sim 15 \mathrm{fF}$ or 530 synaptic vesicles (asterisks in Fig. 4a). Exocytosis of mutant IHCs could be better approximated by using a single component model. However, some residual fast exocytosis $(\sim 5 \mathrm{fF}$ or 210 synaptic vesicles, conversion factor of $24 \mathrm{aF}$ per synaptic vesicle, $\tau \approx 10 \mathrm{~ms}$ ) was evident. This is consistent with the morphological finding of docked vesicles at the $\sim 11$ ribbon-deficient synapses and $\sim 1$ ribbon-containing synapse per mutant IHC (Fig. 1f, Supplementary Table 1). Assuming that fast exocytosis exclusively represents synaptic transmitter release, each of the 10 ribboncontaining synapses of wild-type IHCs $(9.8 \pm 0.9, n=7$ mice $)$ on average holds a large RRP of 53-64 synaptic vesicles. This contrasts with a pool of $\sim 14$ synaptic vesicles (Supplementary Table 1 ) that can be released at comparable speed by the average ribbon-deficient synapse of Bassoon mutants, but does not support synchronous activation of SGNs.

It is not clear how many synaptic vesicles undergo exocytosis at a single afferent synapse after a brief acoustic stimulus in vivo. Postsynaptic recordings from immature IHC afferent synapses showed that transmitter release from a single vesicle is sufficient to depolarize the SGN to threshold. Nonetheless, synchronized release of several vesicles occurs frequently ${ }^{21}$. Our data suggest that synchronous auditory signalling indeed relies on precisely timed release of several synaptic vesicles at the mature afferent IHC synapse, which in turn requires the presence of the ribbon. Parallel and synchronized release of multiple synaptic vesicles at the IHC ribbon synapse is probably required to reduce jitter of postsynaptic action potentials. The achieved precision of stimulus coding enables auditory brainstem neurons to detect submillisecond interaural time differences ${ }^{22}$. In contrast to large auditory brainstem synapses, such as the calyx of Held, where parallel transmitter release at multiple active zones ensures temporally precise excitation of a large neuronal soma, parallel and precisely timed release of multiple vesicles at one ribbon-containing hair cell active zone excites a very small postsynaptic terminal ${ }^{3}$. Possible mechanisms include parallel fusion of docked synaptic vesicles and sequential fusion of more distal, ribbon-associated vesicles to the membrane of previously fused proximal vesicles ${ }^{23}$. We favour the hypothesis that RRP exocytosis is dominated by fusion of docked vesicles $^{1,4,5,24}$, and that the ribbon positions synaptic vesicles close to

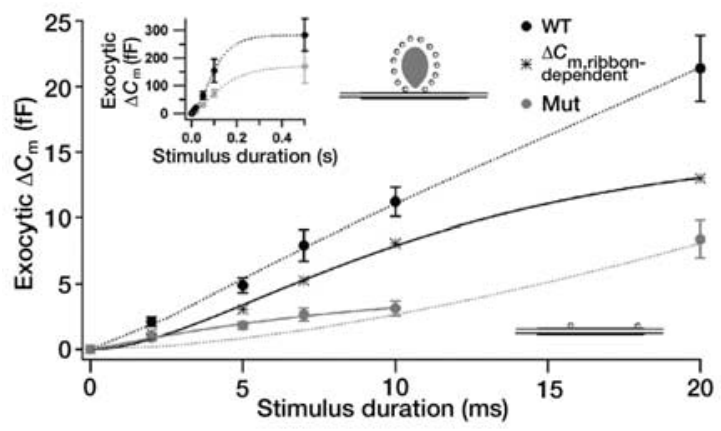

Figure 4 Dissection of ribbon-dependent hair cell exocytosis. Kinetics of exocytosis of wild-type (black circles, $n=26$ ) and mutant (grey circles, $n=24$ ) IHCs analysed as in Fig. 2f. Dotted lines are model fits to wild-type (black): $\Delta C_{\mathrm{m}}=18 \mathrm{fF} \times$ $\left(1-\mathrm{e}^{t / 9 \mathrm{~ms}}\right)^{1.4}+265 \mathrm{fF} \times\left(1-\mathrm{e}^{t / 64 \mathrm{~ms}}\right)^{2.8}$ and mutant (grey): $\Delta C_{\mathrm{m}}=$ $172 \mathrm{fF} \times\left(1-\mathrm{e}^{\mathrm{t} / 107 \mathrm{~ms}}\right)^{1.7}$. The inset shows the full range of data. The first $10 \mathrm{~ms}$ of mutant exocytosis were better approximated by $\Delta C_{\mathrm{m}}=5 \mathrm{fF} \times\left(1-\mathrm{e}^{t / 11 \mathrm{~ms}}\right)$, grey solid line. The difference between wild-type and mutant $\Delta C_{\mathrm{m}}$ is represented by asterisks, approximated by $\Delta C_{\mathrm{m} \text {, ribbon-dependent }}=15 \mathrm{fF} \times\left(1-\mathrm{e}^{\mathrm{t} / \mathrm{ms}}\right)^{2}$ (black solid line). Wildtype and mutant $\Delta C_{\mathrm{m}}$ differed with $P<0.01$ for stimuli below $50 \mathrm{~ms}$, and with $P<0.05$ for $50 \mathrm{~ms}$, but were not significantly different for longer pulses. Cartoons illustrate typical two-dimensional sections of wild-type (top) and mutant (bottom) synapses. All errors are s.e.m. 
$\mathrm{Ca}^{2+}$ channels to ensure efficient stimulus-secretion coupling. However, it was recently suggested that fast exocytosis in hair cells may be mediated by vesicles that are not docked at active zones $^{25,26}$.

To test the idea that synaptic vesicles tethered to the ribbon far from the presynaptic membrane might contribute to fast IHC exocytosis, we compared the number of readily releasable synaptic vesicles to the numbers of docked and total ribbon-associated synaptic vesicles. We analysed 42 ribbon-containing synapses of 8-week-old wild-type IHCs in single, ultrathin sections, and obtained upper estimates of docked and total ribbon-associated synaptic vesicles from ribbon surface calculations on the basis of $4 \mathrm{Pi}$ microscopy (Fig. 1k, Supplementary Table 1 and Supplementary Methods). We estimated between 125 (by electron microscopy) and 203 (by 4Pi microscopy) ribbon-associated synaptic vesicles and 16-30 docked synaptic vesicles; these values are comparable to estimates obtained from ribbons of goldfish bipolar neurons ${ }^{27}$, but smaller than the vesicle load of spheroid bodies in frog saccular hair cells ${ }^{12}$. Hence, the number of readily releasable synaptic vesicles (53-64) exceeded our estimate for the number of docked synaptic vesicles (16-30), suggesting that remote, tethered synaptic vesicles contribute to fast IHC exocytosis. However, it remains possible that we underestimated the number of docked synaptic vesicles owing to chemical fixation ${ }^{28}$, and that the RRP entirely consists of docked synaptic vesicles in mouse IHCs.

Whereas the above results highlight the ribbon's function in synchronous synaptic transmission, the role of the ribbon in sustained exocytosis is less clear. The finding of robust, sustained exocytosis in mutant IHCs (Fig. 4, inset) is surprising in the light of the previously suggested 'conveyor belt' model of the ribbon ${ }^{1,4,5}$. Our finding suggests that slow exocytosis occurs at ribbon-deficient synapses and that additional fusion outside the active zone also contributes $^{18,24,29}$. Indeed, the Bassoon mutants were not completely deaf, indicating that the remaining fast exocytosis and the presence of slow exocytosis support some residual auditory signalling. However, temporally precise sound coding is impaired in this mouse model of synaptic audiopathy. A defect of synchronous IHC synaptic transmission could present a pathomechanism of human auditory neuropathy, and explain the poor speech discrimination that is observed.

\section{Methods}

\section{Animals}

Mice (3- and 8-week-old) with a targeted deletion for exons 4 and 5 of the bassoon gene ${ }^{30}$ and their wild-type littermates were used for experiments. Animal handling followed national ethical guidelines.

\section{Auditory brainstem responses and otoacoustic emissions}

Mice were anaesthetized intraperitoneally with $100 \mathrm{mg} \mathrm{kg}^{-1}$ ketamine and $2 \mathrm{mg} \mathrm{kg}^{-1}$ xylazine. For auditory brainstem responses, tone bursts $(8 / 12 / 16 \mathrm{kHz}, 10 \mathrm{~ms}$ plateau, $1 \mathrm{~ms}$ rise/fall) or clicks of $0.03 \mathrm{~ms}$ were applied in the free field at $20 \mathrm{~Hz}$. Intensities are presented as sound pressure level ( $\mathrm{dB}$ root mean square for tone bursts, $\mathrm{dB}$ peak equivalent for clicks). The difference potential between vertex and mastoid intradermal needles was amplified ( $5 \times 10^{4}$ times), filtered (low-pass, $4 \mathrm{kHz}$; high-pass, $100 \mathrm{~Hz}$ ) and sampled at a rate of $50 \mathrm{kHz}$ for $20 \mathrm{~ms}, 2 \times 2,000$ times to obtain two mean auditory brainstem response traces for each sound intensity. Thresholds were estimated with $10 \mathrm{~dB}$ precision by means of visual inspection. Peak I amplitude was estimated as the difference between peak I and the subsequent negativity. For distortion product otoacoustic emissions (DPOAE), a 24-bit sound card together with the ED1/EC1 speaker system (Tucker-Davis) were used to generate two primary tones ( $\mathrm{f} 1$ and $\mathrm{f} 2$ ) with a ratio of $\mathrm{f} 2 / \mathrm{f} 1=1.2$ and a range for $\mathrm{f} 2$ of 8 to $16 \mathrm{kHz}$. Primary tones were coupled into the ear canal by a custom-made probe containing an MKE-2 microphone (Sennheiser) and adjusted to an intensity of $60 \mathrm{~dB}$ sound pressure level (SPL) at the ear drum. The microphone signal was amplified, sampled by the sound card and analysed by fast Fourier transformation. The peak amplitude of the $2 \mathrm{f} 1-\mathrm{f} 2$ DPOAE and the noise (average power around 2f1-f2) were measured using $\mathrm{fl}=60 \mathrm{~dB}$ SPL as reference.

\section{Patch-clamp recording}

IHCs from the apical coils of freshly dissected organs of Corti were patch-clamped in the perforated-patch configuration as described ${ }^{18}$. The standard pipette solution contained $150 \mathrm{mM}$ caesium gluconate, $13 \mathrm{mM}$ TEA-Cl, $10 \mathrm{mM} \mathrm{CsOH}$-HEPES, $1 \mathrm{mM} \mathrm{MgCl}$ and $250 \mu \mathrm{g} \mathrm{ml}^{-1}$ amphotericin B. The standard bath solution contained $105 \mathrm{mM} \mathrm{NaCl}, 35 \mathrm{mM}$
TEA-Cl, $2.8 \mathrm{mM} \mathrm{KCl}, 10 \mathrm{mM} \mathrm{CaCl}, 1 \mathrm{mM} \mathrm{MgCl}_{2}, 10 \mathrm{mM} \mathrm{NaOH}-\mathrm{HEPES}, 10 \mathrm{mM}$ D-glucose. EPC-9 amplifiers (HEKA-electronics), controlled by Pulse software, were used to low-pass filter and sample currents at $20-40 \mathrm{kHz}$ and at $2-5 \mathrm{kHz}$, respectively. We measured membrane capacitance increments $\left(C_{\mathrm{m}}\right)$ as previously described ${ }^{18}$. Cells were stimulated by depolarizations of different durations to peak $\mathrm{Ca}^{2+}$ current potential at intervals of 30 to $70 \mathrm{~s}$. All currents were leak-corrected using a P/6-protocol. Passive electrical IHC properties are provided in Supplementary Table 2.

\section{Immunostaining, confocal and 4Pi microscopy}

The organs of Corti were fixed with $4 \%$ paraformaldehyde in $120 \mathrm{mM}$ sodium phosphate buffer $(1 \mathrm{~h})$. After incubation of whole-mount preparations for $1 \mathrm{~h}$ in goat serum dilution buffer ( $16 \%$ normal goat serum, $450 \mathrm{mM} \mathrm{NaCl}, 0.3 \%$ Triton X-100, $20 \mathrm{mM}$ phosphate buffer, $\mathrm{pH}$ 7.4) primary antibodies were applied overnight at $4{ }^{\circ} \mathrm{C}$. The following antibodies were used: rabbit anti-Bassoon (Sap7 ${ }^{9}$, diluted 1:1,000), guinea pig antiPiccolo $^{6}$ (1:1,000), RIBEYE rabbit antiserum (a gift from H. Brandstätter, 1:1,000-4,000), mouse IgG1 anti-CtBP2 (BD Biosciences, 1:100-200), rabbit anti-GluR2/3 (Chemicon, 1:1,000), rabbit anti-calbindin (Swants, 1:100). Secondary AlexaFluor-labelled antibodies (Molecular Probes, 1:200) were applied for $1 \mathrm{~h}$. Confocal images were collected using a LSM 510 microscope (Carl Zeiss Jena) and analysed in LSM 5 Image Browser and Adobe Photoshop. Multifocal 4Pi-microscopy with water immersion lenses (NA 1.2; semiaperture angle $64^{\circ}$ ) at a two-photon excitation wavelength of $870 \mathrm{~nm}$ (average power $\sim 1.5 \mathrm{~mW}$ for each of the $4 \mathrm{Pi}$-foci) was done as described before ${ }^{14,15}$ (for details see Supplementary Methods). For 4Pi image restoration, nonlinear deconvolution with a measured point spread function was performed as described previously ${ }^{15}$.

\section{Transmission electron microscopy}

Cochleas were fixed by perfusing $2 \%$ glutaraldehyde in Milloning buffer ( $\mathrm{pH} 7.4$ ) through the oval and round windows, after gently opening the apex, and were then immersed in the same fixative overnight, rinsed in Milloning, and postfixed in $2 \%$ osmium tetroxide for $1 \mathrm{~h}$. They were then rinsed in Milloning twice, dehydrated in a graded ethanol series $(30-100 \%)$ and in propylene oxide, and embedded in Epon. The cochlear coils were separated, and the upper second turn was remounted for semi-thin and thin longitudinal sectioning, allowing access to several IHC synaptic poles on the same section. Ultrathin sections (70-100 nm; Leica-Reichert) were counter-stained with uranyl acetate and lead citrate, and observed with a Hitachi 7100 electron microscope.

\section{Data analysis}

Changes in $C_{\mathrm{m}}$ were estimated as the difference between the mean $C_{\mathrm{m}}$ after the end of the depolarization and the mean pre-pulse $C_{\mathrm{m}}$ (the initial $40 \mathrm{~ms}$ after the depolarization was omitted). Mean $\Delta C_{\mathrm{m}}$ and $\mathrm{Ca}^{2+}$ current estimates present grand averages calculated from the mean estimates of individual IHCs. This avoided dominance of IHCs contributing more sweeps. All voltages were corrected for liquid junction potentials. Values were expressed as means \pm s.e.m. and compared using Student's unpaired $t$-tests, with single, double and triple asterisks indicating $P<0.05,0.02$ and 0.01 , respectively.

Received 22 November 2004; accepted 28 January 2005; doi:10.1038/nature03418.

1. Fuchs, P. A., Glowatzki, E. \& Moser, T. The afferent synapse of cochlear hair cells. Curr. Opin. Neurobiol. 13, 452-458 (2003).

2. Smith, C. A. \& Sjostrand, F. S. A synaptic structure in the hair cells of the guinea pig cochlea. J. Ultrastruct. Res. 5, 184-192 (1961).

3. Liberman, M. C. Single-neuron labeling in the cat auditory nerve. Science 216, 1239-1241 (1982),

4. Sterling, P. \& Matthews, G. Structure and function of ribbon synapses. Trends Neurosci. 28, 20-29 (2005)

5. Lagnado, L. Ribbon synapses. Curr. Biol. 13, R631 (2003).

6. Schmitz, F., Konigstorfer, A. \& Sudhof, T. C. RIBEYE, a component of synaptic ribbons: a protein's journey through evolution provides insight into synaptic ribbon function. Neuron 28, 857-872 (2000).

7. Dick, O. et al. Localization of the presynaptic cytomatrix protein Piccolo at ribbon and conventional synapses in the rat retina: comparison with Bassoon. J. Comp. Neurol. 439, 224-234 (2001).

8. tom Dieck, S. et al. Molecular dissection of the photoreceptor ribbon synapse: physical interaction of Bassoon and RIBEYE is essential for the assembly of the ribbon complex. J. Cell Biol. (in the press); published online 22 February 2005 (doi:10.1083/jcb.200408157).

9. tom Dieck, S. et al. Bassoon, a novel zinc-finger CAG/glutamine-repeat protein selectively localized at the active zone of presynaptic nerve terminals. J. Cell Biol. 142, 499-509 (1998).

10. Dick, O. et al. The presynaptic active zone protein bassoon is essential for photoreceptor ribbon synapse formation in the retina. Neuron 37, 775-786 (2003).

11. Paillart, C., Li, J., Matthews, G. \& Sterling, P. Endocytosis and vesicle recycling at a ribbon synapse. J. Neurosci. 23, 4092-4099 (2003).

12. Lenzi, D., Crum, J., Ellisman, M. H. \& Roberts, W. M. Depolarization redistributes synaptic membrane and creates a gradient of vesicles on the synaptic body at a ribbon synapse. Neuron $\mathbf{3 6}$, 649-659 (2002).

13. Holt, M., Cooke, A., Wu, M. M. \& Lagnado, L. Bulk membrane retrieval in the synaptic terminal of retinal bipolar cells. J. Neurosci. 23, 1329-1339 (2003).

14. Hell, S. \& Stelzer, E. H. K. Properties of a 4Pi-confocal fluorescence microscope. J. Opt. Soc. Am. A 18, 2159-2166 (1992).

15. Egner, A., Jakobs, S. \& Hell, S. W. Fast 100-nm resolution three-dimensional microscope reveals structural plasticity of mitochondria in live yeast. Proc. Natl Acad. Sci. USA 99, 3370-3375 (2002).

16. Kemp, D. T. Stimulated acoustic emissions from within the human auditory system. J. Acoust. Soc. Am. 64, 1386-1391 (1978).

17. Starr, A., Picton, T. W., Sininger, Y., Hood, L. J. \& Berlin, C. I. Auditory neuropathy. Brain 119 741-753 (1996).

18. Moser, T. \& Beutner, D. Kinetics of exocytosis and endocytosis at the cochlear inner hair cell afferent synapse of the mouse. Proc. Natl Acad. Sci. USA 97, 883-888 (2000). 
19. Shnerson, A. Devigne, C. \& Pujol, R. Age-related changes in the C57BL/6J mouse cochlea. II. Ultrastructural findings. Brain Res. 254, 77-88 (1981).

20. Neher, E. Vesicle pools and $\mathrm{Ca}^{2+}$ microdomains: new tools for understanding their roles in neurotransmitter release. Neuron 20, 389-399 (1998).

21. Glowatzki, E. \& Fuchs, P. A. Transmitter release at the hair cell ribbon synapse. Nature Neurosci. 5, 147-154 (2002)

22. Trussell, L. O. Synaptic mechanisms for coding timing in auditory neurons. Annu. Rev. Physiol. $\mathbf{6 1}$ 477-496 (1999).

23. Heidelberger, R., Heinemann, C., Neher, E. \& Matthews, G. Calcium dependence of the rate of exocytosis in a synaptic terminal. Nature 371, 513-515 (1994).

24. Zenisek, D., Steyer, J. A. \& Almers, W. Transport, capture and exocytosis of single synaptic vesicles at active zones. Nature 406, 849-854 (2000).

25. Edmonds, B. W., Gregory, F. D. \& Schweizer, F. E. Evidence that fast exocytosis can be predominantly mediated by vesicles not docked at active zones in frog saccular hair cells. J. Physiol. (Lond.) 560, 439-450 (2004).

26. Spassova, M. A. et al. Evidence that rapid vesicle replenishment of the synaptic ribbon mediates recovery from short-term adaptation at the hair cell afferent synapse. J. Assoc. Res. Otolaryngol. 5 376-390 (2004)

27. von Gersdorff, H., Vardi, E., Matthews, G. \& Sterling, P. Evidence that vesicles on the synaptic ribbon of retinal bipolar neurons can be rapidly released. Neuron 16, 1221-1227 (1996).

28. Smith, J. E. \& Reese, T. S. Use of aldehyde fixatives to determine the rate of synaptic transmitter release J. Exp. Biol. 89, 19-29 (1980)

29. Beutner, D., Voets, T., Neher, E. \& Moser, T. Calcium dependence of exocytosis and endocytosis at the cochlear inner hair cell afferent synapse. Neuron 29, 681-690 (2001).

30. Altrock, W. D. et al. Functional inactivation of a fraction of excitatory synapses in mice deficient for the active zone protein bassoon. Neuron 37, 787-800 (2003).

Supplementary Information accompanies the paper on www.nature.com/nature.

Acknowledgements We would like to thank A. Brandt and A. Schoenle for providing custom analysis software; S. Anderson and S. Lacas-Gervais for help in setting up auditory physiology and immunohistochemistry in the InnerEarLab, respectively; and J. H. Brandstaetter, F. Wolf and S. W. Hell for discussions and suggestions; members of the InnerEarLab for counting of spots and discussion; E. Neher, T. Sakaba, L. Lagnado, C. Kubisch, M. C. Liberman and E. Livesey for comments on the manuscript; F. Kirchhoff and M. Lenoir for help with confocal and electron microscopy, respectively; and M. Köppler, F. Tribillac and C. Cazevieille for technical assistance. We would like to thank M. Eybalin for initial collaboration. This work was supported by grant from the Deutsche Forschungsgemeinschaft to T.M. and to E.D.G., by a Tandem-Project of the Max Planck Society (to E. Neher and T.M.), a Human Frontiers in Science Program grant to T.M., a grant from the Fonds der Chemischen Industrie to E.D.G, and a grant from AcouphènesLanguedoc-Roussillon to J.-L. Puel.

Competing interests statement The authors declare that they have no competing financial interests.

Correspondence and requests for materials should be addressed to T.M. (tmoser@gwdg.de).

Essential role of TRPC channels in the guidance of nerve growth cones by brain-derived neurotrophic factor

\author{
Yan Li ${ }^{1,2 *}$, Yi-Chang Jia ${ }^{1,2 *}$, Kai Cui ${ }^{1,2 *}$, Ning $\mathbf{L i}^{1,2}$, Zai-Yu Zheng ${ }^{1,2}$, \\ Yi-zheng Wang ${ }^{1}$ \& Xiao-bing Yuan
}

${ }^{1}$ Institute of Neuroscience, Shanghai Institutes for Biological Sciences, Chinese Academy of Sciences, Shanghai 200031, China

${ }^{2}$ Graduate School of the Chinese Academy of Sciences, Shanghai 200031, China

* These authors contributed equally to this work

Brain-derived neurotrophic factor (BDNF) is known to promote neuronal survival and differentiation ${ }^{1}$ and to guide axon extension both in vitro ${ }^{2,3}$ and in vivo ${ }^{4}$. The BDNF-induced chemoattraction of axonal growth cones requires $\mathrm{Ca}^{2+}$ signalling ${ }^{3}$, but how $\mathrm{Ca}^{2+}$ is regulated by BDNF at the growth cone remains largely unclear. Extracellular application of BDNF triggers membrane currents resembling those through TRPC (transient receptor potential canonical) channels in rat pontine neurons ${ }^{5}$ and in Xenopus spinal neurons ${ }^{6}$. Here, we report that in cultured cerebellar granule cells, TRPC channels contribute to the BDNF-induced elevation of $\mathrm{Ca}^{2+}$ at the growth cone and are required for BDNF-induced chemo-attractive turning. Several members of the TRPC family are highly expressed in these neurons, and both $\mathrm{Ca}^{2+}$ elevation and growth-cone turning induced by BDNF are abolished by pharmacological inhibition of TRPC channels, overexpression of a dominant-negative form of TRPC3 or TRPC6, or downregulation of TRPC3 expression via short interfering RNA. Thus, TRPC channel activity is essential for nerve-growth-cone guidance by BDNF.

Growing axons are guided to their target cells by diffusible and substrate-bound guidance cues ${ }^{7}$, among which BDNF exerts both attractive and repulsive actions on growth cones ${ }^{2-4}$. In the present study, we first examined the guidance action of BDNF on the growth cones of cultured rat cerebellar granule cells, the migration of which is stimulated by $\mathrm{BDNF}^{8}$. A microscopic gradient of BDNF was produced by pulsatile application of BDNF-containing solution with a micropipette near growth cones (see Methods). This BDNF gradient caused marked growth-cone turning towards the pipette within $30 \mathrm{~min}$ (Fig. 1a). Control experiments showed that application of vehicle solution (PBS) had no effect on growth-cone extension (Fig. 1b). The chemo-attractive effect of BDNF required activation of the high-affinity BDNF receptor $\operatorname{TrkB}$, as it was abolished by bath application of K252a (Fig. 1c), an inhibitor of TrkB ${ }^{9}$. Furthermore, BDNF-induced growth-cone attraction was abolished in a $\mathrm{Ca}^{2+}$-free medium (Fig. 1c), consistent with results in cultured Xenopus spinal neurons ${ }^{3}$. The attraction was also blocked by pre-incubation with BAPTA-AM $(2 \mu \mathrm{M})$, a membranepermeable $\mathrm{Ca}^{2+}$ buffer, or with thapsigargin $(1 \mu \mathrm{M})$, which depletes intracellular $\mathrm{Ca}^{2+}$ stores (Fig. 1c). Therefore, $\mathrm{Ca}^{2+}$ influx through plasma membrane $\mathrm{Ca}^{2+}$ channels and $\mathrm{Ca}^{2+}$ release from internal stores are both required for growth-cone turning induced by BDNF.

It is known that netrin-1-induced growth-cone attraction requires $\mathrm{Ca}^{2+}$ influx through $\mathrm{L}$-type voltage-dependent $\mathrm{Ca}^{2+}$ channels (VDCCs) and $\mathrm{Ca}^{2+}$ release from internal stores ${ }^{10}$. However, we found that BDNF-induced growth-cone attraction in rat cerebellar granule cells was unaffected by bath application of nifedipine $(5 \mu \mathrm{M})$ and $\omega$-conotoxin MVIIC $(5 \mu \mathrm{M})$-specific blockers of L- and P/Q-type VDCCs, respectively-or by applying ryanodine at a high concentration $(100 \mu \mathrm{M}$, ref. 10) that blocks ryanodine-sensitive channels of internal stores (Fig. 1c). Thus, $\mathrm{Ca}^{2+}$ influx through VDCCs and internal $\mathrm{Ca}^{2+}$ release through ryanodine channels are unlikely to contribute to BDNF-induced growth-cone turning. Rapid neuronal depolarization through the activation of a saxitoxin-sensitive $\mathrm{Na}^{+}$channel $\left(\mathrm{Na}_{\mathrm{v}} 1.9\right)$ may be evoked by $\mathrm{BDNF}^{11}$, but neither saxitoxin $(10 \mathrm{nM})$ nor tetrodotoxin $(50 \mathrm{nM}$, data not shown) had an effect on BDNF-induced growthcone turning (Fig. 1c), suggesting that $\mathrm{Na}^{+}$-channel-dependent depolarization is not involved.

Because $\mathrm{Ca}^{2+}$-permeant channels other than VDCCs appear to mediate the $\mathrm{Ca}^{2+}$ influx required for BDNF chemo-attraction, we examined the involvement of $\mathrm{Ca}^{2+}$-permeant TRPC channels. When granule cells were incubated in SKF-96365 $(3 \mu \mathrm{M})$, a relatively nonspecific inhibitor of store-operated $\mathrm{Ca}^{2+}$ entry and of TRP channels ${ }^{5,12}$, BDNF-induced growth-cone turning was completely abolished (Fig. 1a, b), suggesting that $\mathrm{Ca}^{2+}$ entry through TRP channels may be involved. The blocking effect of SKF-96365 is specific to BDNF, because this drug had no effect on growth-cone turning induced by a glutamate gradient (Fig. 1b, $0.5 \mathrm{mM}$ ). The latter turning was abolished instead by antagonists of NMDA ( $N$-methyl-D-aspartate) receptors, AMPA ( $\alpha$-amino-3hydroxy-5-methyl-4-isoxazole propionic acid) receptors and L-type VDCCs, but not by inhibitors of metabotropic glutamate receptors (Supplementary Fig. 1). Similarly, the repulsive turning triggered by a gradient of stromal cell-derived factor 1 (SDF-1, $20 \mu \mathrm{g} \mathrm{ml}^{-1}$ ), a chemokine known to repel the growth cones of these granule cells ${ }^{13}$, was not affected by SKF-96365 (Fig. 1b).

Additional studies were carried out to examine signalling events triggered by BDNF, using pharmacological treatments (Fig. 2c). 